\title{
Multi-Beam Focal Plane Arrays with Digital Beamforming for High Precision Space- Borne Ocean Remote Sensing
}

lupikov, Oleg A.; Ivashina, Mariana V.; Skou, Niels; Cappellin, Cecilia; Pontoppidan, Knud; van 't Klooster, Cornelis G. M.

Published in:

I E E E Transactions on Antennas and Propagation

Link to article, DOI:

10.1109/TAP.2017.2763174

Publication date:

2018

Document Version

Peer reviewed version

Link back to DTU Orbit

Citation $(A P A)$ :

lupikov, O. A., Ivashina, M. V., Skou, N., Cappellin, C., Pontoppidan, K., \& van 't Klooster, C. G. M. (2018). MultiBeam Focal Plane Arrays with Digital Beamforming for High Precision Space-Borne Ocean Remote Sensing. I E E E Transactions on Antennas and Propagation, 66(2), 737 - 748. https://doi.org/10.1109/TAP.2017.2763174

\section{General rights}

Copyright and moral rights for the publications made accessible in the public portal are retained by the authors and/or other copyright owners and it is a condition of accessing publications that users recognise and abide by the legal requirements associated with these rights.

- Users may download and print one copy of any publication from the public portal for the purpose of private study or research.

- You may not further distribute the material or use it for any profit-making activity or commercial gain

- You may freely distribute the URL identifying the publication in the public portal 


\title{
Multi-Beam Focal Plane Arrays with Digital Beamforming for High Precision Space-Borne Ocean Remote Sensing
}

\author{
O. A. Iupikov, Student Member, IEEE, M. V. Ivashina, Senior Member, IEEE, N. Skou, Fellow, IEEE, \\ C. Cappellin, Member, IEEE, K. Pontoppidan, and K. van 't Klooster
}

\begin{abstract}
The present-day ocean remote sensing instruments that operate at low microwave frequencies are limited in spatial resolution and do not allow for monitoring of the coastal waters. This is due the difficulties of employing a large reflector antenna on a satellite platform, and generating high-quality pencil beams at multiple frequencies. Recent advances in digital beamforming focal-plane-arrays (FPAs) have been exploited in the current work to overcome the above problems. A holistic design procedure for such novel multi-beam radiometers has been developed, where (i) the antenna system specifications are derived directly from the requirements to oceanographic surveys for future satellite missions; and (ii) the numbers of FPA elements/receivers are determined through a dedicated optimum beamforming procedure minimizing the distance to coast. This approach has been applied to synthesize FPAs for two alternative radiometer systems: a conical scanner with an off-set parabolic reflector, and stationary wide-scan torus reflector system; each operating at $\mathrm{C}, \mathrm{X}$ and $\mathrm{Ku}$ bands. Numerical results predict excellent beam performance for both systems with as low as $0.14 \%$ total received power over the land.
\end{abstract}

Index Terms-reflector antenna feeds, array antennas, microwave radiometers

\section{INTRODUCTION}

Microwave radiometry is a highly versatile method of remote sensing, capable of delivering measurements of a variety of geophysical properties of the ocean and atmosphere, even through clouds. The retrieval methods distinguish the individual effects of different geophysical properties by using the frequency and polarization state of the microwave radiation detected by the antenna. Despite such versatility, the exploitation of microwave radiometry in Earth observation has been constrained by the difficulties of generating antenna beams with low side-lobes and cross-polarization, and accomodating

O. A. Iupikov and M. V. Ivashina are with the Signals and Systems Department of the Chalmers University of Technology, Gothenburg, Sweden, e-mail: oleg.iupikov@chalmers.se, marianna.ivashina@chalmers.se.

N. Skou is with the DTU-Space, Technical University of Denmark, Kgs. Lyngby, Denmark, e-mail: ns@space.dtu.dk.

C. Cappellin and K. Pontoppidan are with the TICRA, Copenhagen, Denmark, e-mail: cc@ticra.com,kp@ticra.com.

K. van 't Klooster is with the Technische Universiteit Eindhoven (previously with European Space Agency), The Netherlands, e-mail: kvtklooster@gmail.com.

The work has been carried out in the framework of the 'Advanced MultiBeam Radiometers' project that is a collaborative effort between TICRA, DTU-Space (Denmark), HPS (Germany) and Chalmers, partially funded by European Space Agency (ESA), the Swedish Research Council and National Space Board grants.

Manuscript received April xx, 20xx; revised January xx, 20xx. several feeds operating at different frequencies, when deploying the antenna on a satellite platform [1]. In particular, for high resolutions demanded by oceanographers, the current antenna designs would need to be scaled up to a physical size that is too large to be achievable or affordable within typical Earth observation infrastructure budgets. For this reason, space agencies have been seeking solutions to overcome what seems at present to be an unpassable barrier to further significant improvement of a whole class of remote sensing methods.

The European Space Agency (ESA) is currently considering the ocean missions where extreme weather, climate variability, coastal and marginal-ice-zone studies are strong drivers [2], [3]. These studies require a very high radiometric resolution, i.e. around $0.25 \mathrm{Kelvin}$, and at the same time a high spatial resolution approaching $20 \mathrm{~km}$ at $\mathrm{C}$ and $\mathrm{X}$ bands and $10 \mathrm{~km}$ at $\mathrm{Ku}$ band (see Table I) [4]. This desired performance represents a significant improvement compared with existing space-borne radiometer systems, such as AMSR-E and WindSat [5], [6]. They feature spatial resolutions around $55 \mathrm{~km}, 35 \mathrm{~km}$, and 20 $\mathrm{km}$ at the $\mathrm{C}, \mathrm{X}$, and $\mathrm{Ku}$ bands, and the radiometric resolution provided by AMSR-E is $0.3 \mathrm{~K}$ at $\mathrm{C}$ band and $0.6 \mathrm{~K}$ at $\mathrm{X}$ and $\mathrm{Ku}$ band, while for WindSat it is around $0.7 \mathrm{~K}$. Moreover, future systems are required to provide valid observations up to very short distances from the coastline, i.e. $5-15 \mathrm{~km}$, while the existing systems can observe only up to $\sim 100 \mathrm{~km}$.

It can be shown that the desired spatial resolution calls for a reflector antenna with $\sim 5 \mathrm{~m}$ aperture diameter [7]; that is very challenging considering the experience of SMAP mission, which has a $6 \mathrm{~m}$ reflector [8], [9]. On the other hand, for all three frequency bands the bandwidths are limited to a few hundreds of $\mathrm{MHz}$, that makes it possible (at least in theory) to achieve very low noise temperatures of the receivers. However, even the most optimistic receiver noise properties cannot ensure the required radiometric resolution when considering a single beam scanning system (see Fig. 1(a)). For a scanner, the only solution is to employ several independent beams per frequency, and improve radiometric resolution by integrating several footprints. This calls for a large number of overlapping beams - in the present case up to 30 beams at Ku-band. An alternative is a push-broom system [10], [11], where many beams cover the swath simultaneously, as illustrated in Fig. 1(b). Using traditional feeds, each antenna beam is associated with its own receiver, and high radiometric resolution is achieved thanks to the fact that the signals associated with multiple across-track footprints do not have to be multiplexed 


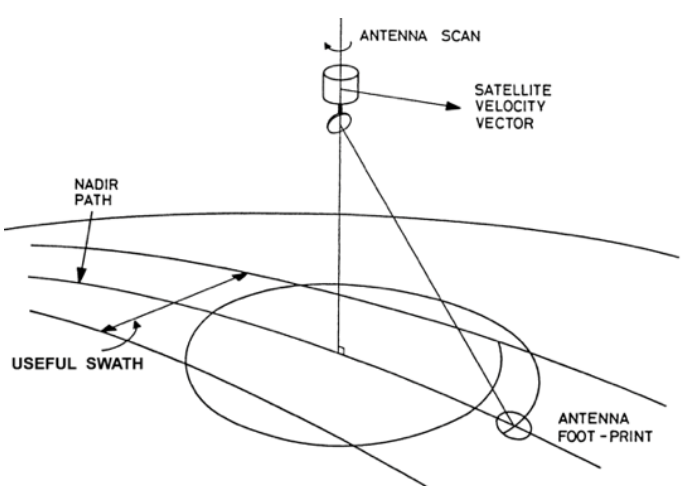

(a)

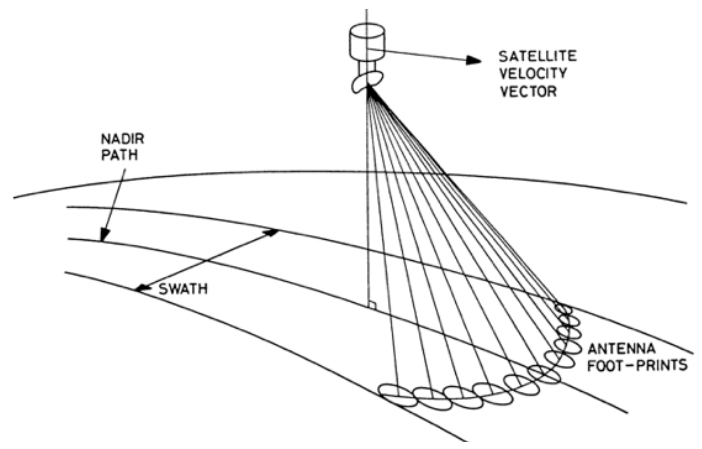

(b)

Fig. 1. Operational principle of (a) the conical scan and (b) push-broom microwave radiometers for ocean remote sensing.

through a single receiver. Radiometric resolution is no longer a problem, but a more complicated antenna design (a tilted parabolic torus reflector) is needed as well as many beams for the present case up to 156 at $\mathrm{Ku}$-band. Realizing these, while correcting for the antenna field distortions causing the well-known triangular footprints and their large separation on the Earth [10], [11], represents a great challenge. Also the implementation of this concept should be feasible regarding the resource requirements, i.e. the size, mass and power consumption.

As demonstrated in this study (see Sec. IV), the above radiometric requirements cannot be fulfilled by using traditional cluster feeds of horns (in one-horn-per-beam configuration), employed at such multi-frequency radiometer antennas. Recent studies supported by ESA [12]-[15] have identified a promising solution that originates from the field of radio astronomy [16]-[22], where instrument designs have evolved to meet the high-sensitivity and large-coverage requirements of ground based observatories exploring the universe without the above challenges. This solution is based on 'dense' focal plane arrays (FPAs), where many small antenna elements take part in the formation of each beam (so that each beam can be optimized for high performace, even far off-axis beams) and the same element takes part in the formation of multiple beams (so that the footprints overlap), thanks to digital beamforming. Dense FPAs capable of generating multiple beams find their application not only in radio astronomy, but also in telecom applications, where they are referred to as multibeam antennas in multi-feed per beam (MFB) configuration.
The technology used in space for telecom MFB applications is mature and typically used for multi beam missions in L-band, see for example the Thuraya satellite [23] and the Inmarsat satellites [24]. For example, Thuraya employs an L-band 128element dipole array feeding a $12.25 \times 16 \mathrm{~m}$ mesh transmitreceive reflector, and generates more than 200 pencil beams that can be redirected on-orbit [23]. Recent developments have been made for MFB applications in Ka-band, where [25], [26] and [27] have developed compact and high efficient feed arrays, made by closely spaced horn antennas excited by a beam forming network. It is noted that MFB antennas for telecom applications are located on the geostationary orbit and are driven by requirements which differ from the ones for radiometric applications treated in the present paper.

The requirements for radiometer systems will be discussed in Sec. II, and translated into antenna system specifications and beam characteristics to optimize for. The reflector antenna geometries used in this study are briefly described in Sec. III. Section V will cover the synthesis of FPAs for such systems, and include the following original contributions: (i) a dedicated optimum-beamforming algorithm minimizing the distance to coast; (ii) optimized antenna patterns and radiometric parameters - as obtained for the half-wavelength dipole element FPAs - that fulfill all above requirements with almost twice less elements in comparison to the conventional conjugate-fieldmatching optimization approach [12]; and (iii) validation of the simplified array model with the assumed identical embeded element patterns [12], [14] across the full MoM model for the purpose of the FPA synthesis. Finally, digital receiver resource requirements will be considered in Sec. VI.

\section{FROM OCEONAGRAPHIC REQUIREMENTS TO ANTENNA SYSTEM SPECIFICATIONS}

The requirements for future missions in Table I are defined in terms of performance metrics for oceanographic surveys, i.e. spatial resolution, radiometric resolution, bias and distance to coast. Since these terms are not commonly known by antenna designers, next we will summarize their definitions and use these to derive the antenna system specifications.

\section{A. Spatial resolution $(\mathrm{FP}) \Rightarrow$ reflector diameter}

The radiometer spatial resolution is defined by the footprint (FP), which is the area on the Earth surface bounded by the projection of the radiation pattern at $-3 \mathrm{~dB}$ level. Sometimes the footprint size along track is of importance (when e.g. the scan rotation rate should be calculated), sometimes we discuss the footprint across-track (when e.g. the radiometer sampling rate should be found). But in order to compare different radiometric systems it is convenient to have a one number as a figure of merit. That can be an arithmetic (like in Eq. (1)) or geometric mean of the FP size along and across track.

The required spatial resolution in Table 1 is defined in terms of the average footprint size on the Earth's surface:

$$
\mathrm{FP}=\left(Y \times \theta_{3 \mathrm{dBT}}+Y \times \theta_{3 \mathrm{dBL}} / \cos \nu\right) / 2,
$$


where $\theta_{3 \mathrm{dBL}}$ and $\theta_{3 \mathrm{dBT}}$ are the half-power beamwidths of the antenna main beam along the elevation ("along track") and azimuth ("across track") directions, respectively, expressed in radians; $\nu$ is the incidence angle as measured from the normal to the Earth's surface and $Y$ is the distance from the satellite to the observation point on the Earth.

The FP is directly related to the antenna beamwidth, and hence determines its aperture diameter. This diameter should be at least $5 \mathrm{~m}$ for the present case $\left(\nu=53^{\circ}\right.$ and $Y=1243$ $\mathrm{km}$ ) in order to realize the FP of $20 \mathrm{~km}$ at C-band. Since for the considered system, the same antenna is used at different bands, the same FP cannot be obtained at both $\mathrm{C}$ - and X-bands. The required FP shall therefore be considered a guideline and values both slightly above and below are acceptable. The important factor is that the beam crossover points should be at the $-3 \mathrm{~dB}$ level. This means that if the FP is reduced, more beams are needed to cover a particular region on the Earth.

TABLE I

RADIOMETRIC REQUIREMENTS FOR FUTURE OCEAN MISSIONS

\begin{tabular}{|c|c|c|c|c|c|c|}
\hline $\begin{array}{c}\text { Freq., } \\
{[\mathrm{GHz}]}\end{array}$ & $\begin{array}{c}\text { Band } \\
\text { width, } \\
{[\mathrm{MHz}]}\end{array}$ & $\begin{array}{c}\text { Polari- } \\
\text { zation }\end{array}$ & $\begin{array}{c}\text { Radiometric } \\
\text { resolution, } \\
{[\mathrm{K}]}\end{array}$ & $\begin{array}{c}\text { Bias, } \\
{[\mathrm{K}]}\end{array}$ & $\begin{array}{c}\text { Spatial } \\
\text { resolution, } \\
{[\mathrm{km}]}\end{array}$ & $\begin{array}{c}\text { Dist.to } \\
\text { coast, } \\
{[\mathrm{km}]}\end{array}$ \\
\hline 6.9 & 300 & $\mathrm{~V}, \mathrm{H}$ & 0.30 & 0.25 & 20 & $5-15$ \\
\hline 10.65 & 100 & $\begin{array}{c}\mathrm{V}, \mathrm{H}, \\
\mathrm{S}_{3}, \mathrm{~S}_{4}\end{array}$ & 0.22 & 0.25 & 20 & $5-15$ \\
\hline 18.7 & 200 & $\begin{array}{c}\mathrm{V}, \mathrm{H}, \\
\mathrm{S}_{3}, \mathrm{~S}_{4}\end{array}$ & 0.25 & 0.25 & 10 & $5-15$ \\
\hline
\end{tabular}

\section{B. Bias $(\Delta T) \Rightarrow$ acceptable cross-polarization power}

Bias is a systematic error of the measured brightness temperature of the sea. For full polarization radiometers, $\Delta \mathrm{T}$ is typically driven by polarization leakage. The approximate values of the sea temperature for the incidence angle $53^{\circ}$ are $T_{\mathrm{v}}=150 \mathrm{~K}$ and $T_{\mathrm{h}}=75 \mathrm{~K}$ in vertical and horizontal polarizations, respectively. To measure $T_{\mathrm{h}}$, one can select the co-polar component as the horizontal polarization. The crosspolarization component of the pattern, however, will pick up the vertical component of the radiation from the sea, which has a temperature of $150 \mathrm{~K}$. Using the assumption that the amount of radiation received from the sky is negligible, it is sufficient to consider the antenna pattern in the angular region covering the Earth only, and hence compute the total temperature as $T_{\mathrm{b}}=T_{\mathrm{v}} P_{\text {cross }}+T_{\mathrm{h}} P_{\text {co }}$, where $P_{\text {co }}$ and $P_{\text {cross }}$ are the co- and cross-polarization received powers in the angular region of the Earth, normalized to the total field power $\left(P_{\mathrm{co}}+P_{\text {cross }}\right)$ in the same angular region. Then, $\Delta \mathrm{T}$ can be found as

$$
\Delta \mathrm{T}=T_{\mathrm{b}}-T_{\mathrm{h}}=\left(T_{\mathrm{v}}-T_{\mathrm{h}}\right) P_{\text {cross }},
$$

where $P_{\text {cross }}$ is the acceptable relative cross-polarization power of the antenna pattern that covers the Earth. Using (2), one can show that the requirement for the $\Delta T=0.25 \mathrm{~K}$ can be satisfied only if $P_{\text {cross }}$ does not exceed $0.34 \%$.

\section{Bias $(\Delta T) \Rightarrow$ Distance to coast $\left(D_{c}\right)=$ acceptable side lobes}

Table I states that $D_{\mathrm{c}}$ should be $5-15 \mathrm{~km}$, when measured from the FP. The reason behind this requirement is that the

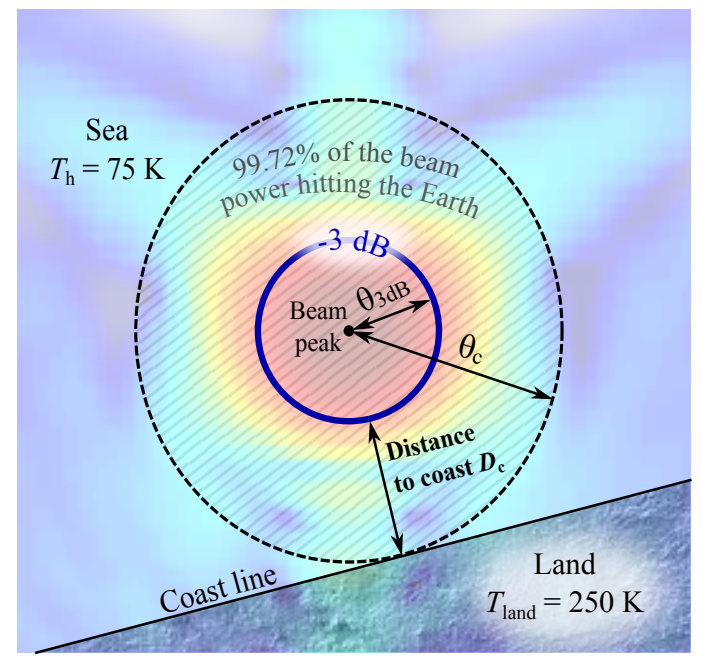

Fig. 2. Footprint falling on the sea near a coast: illustration for the definition of the distance to coast $D_{\mathrm{c}}$.

brightness temperature of the land is much higher than that of the sea. This means that the power in the antenna pattern over land must be sufficiently small. In order to assess the influence from the land the cross polarization can be neglected. The brightness temperature of the land surface is about $T_{\text {land }}=$ $250 \mathrm{~K}$. Assuming the measurements at horizontal polarization, the sea temperature is around $T_{\mathrm{h}}=75 \mathrm{~K}$. If there is no land below the satellite, the radiometer will receive an amount of power proportional to $T_{\mathrm{h}} P_{\mathrm{co}}$. If the satellite covers both the land and sea regions, the power from the sea is $T_{\mathrm{h}}\left(P_{\mathrm{co}}-P_{\text {land }}\right)$, where $P_{\text {land }}$ is the relative co-polarization power in the land region. The signal from the land is $T_{\text {land }} P_{\text {land }}$. The measured temperature and $\Delta \mathrm{T}$ are therefore

$$
\begin{gathered}
T_{\mathrm{b}}=T_{\mathrm{h}} \frac{P_{\mathrm{co}}-P_{\text {land }}}{P_{\mathrm{co}}}+T_{\text {land }} \frac{P_{\text {land }}}{P_{\mathrm{co}}}, \\
\Delta \mathrm{T}=T_{\mathrm{b}}-T_{\mathrm{h}}=\left(T_{\text {land }}-T_{\mathrm{h}}\right) \frac{P_{\text {land }}}{P_{\mathrm{co}}} .
\end{gathered}
$$

We will now determine $D_{\mathrm{c}}$ by the help of Fig. 2, where we have assumed a straight coastline and a circular symmetric beam with the beamwidth of $\theta_{3 \mathrm{~dB}}$. The beam is located over the sea and the distance from the peak to the coast is indicated by the angle $\theta_{\mathrm{c}}$, while the power in the cone with semi-angle $\theta_{\mathrm{c}}$ is denoted by $P_{\mathrm{c}}$. The power outside this cone is $P_{\mathrm{co}}-P_{\mathrm{c}}$ and approximately half of this power will fall on the land, so we have $P_{\text {land }}=\left(P_{\mathrm{co}}-P_{\mathrm{c}}\right) / 2$. Substituting this into (4) gives

$$
\frac{P_{\mathrm{c}}}{P_{\mathrm{co}}}=1-\frac{2 \Delta \mathrm{T}}{T_{\text {land }}-T_{\mathrm{h}}} .
$$

Inserting the required $\Delta \mathrm{T} \leq 0.25 \mathrm{~K}$ in (5) gives

$$
\frac{P_{\mathrm{c}}}{P_{\mathrm{co}}} \geq 1-\frac{2 \times 0.25}{T_{\text {land }}-T_{\mathrm{h}}}=0.9972 .
$$

This equation shows that the required accuracy is obtained when the coastline is located outside a cone around the main beam containing $99.72 \%$ of the total power on the Earth. 
Hence, in order to reduce $D_{\mathrm{c}}$, one should minimize this cone. Then $D_{\mathrm{c}}$ can be defined as the angular difference $\theta_{\mathrm{c}}-\theta_{3 \mathrm{~dB}}$ projected on the Earth surface, i.e.,

$$
D_{\mathrm{c}}=Y \sin \theta_{\mathrm{c}}-Y \sin \theta_{3 \mathrm{~dB}} \approx\left(\theta_{\mathrm{c}}-\theta_{3 \mathrm{~dB}}\right) Y .
$$

For non-symmetric patterns, the same procedure can be used, where the beamwidth $\theta_{3 \mathrm{~dB}}$ is assumed to be equal to the average beamwidth for all antenna pattern cuts.

It should be noted that due to non-zero incidence angle $\nu$ the shape of the footprint stretches in along-track direction by the factor $1 / \cos (\nu)$. Therefore, the distance-to-coast in along-track direction will also be factor $1 / \cos (\nu)$ larger than the calculated one from eq. (7) if the reflector antenna beam is circular-symmetric. However, for the present case the beamformer minimizes $D_{\mathrm{c}}$, making the beam elliptical with major axis in across-track direction. This elliptical beam results in a footprint close to circular-symmetric, and therefore the initial assumption of a circular antenna beam gives close approximation of the $D_{\mathrm{c}}$ value.

\section{Radiometric resolution $\left(\Delta T_{\min }\right) \Rightarrow$ number of beams}

Radiometric resolution is the smallest change in input brightness temperature that can be detected. For a fullpolarization radiometer it can be found as

$$
\Delta T_{\min }=\frac{T_{\mathrm{sys}}}{\sqrt{N_{b} B \tau}}=\frac{T_{\mathrm{rec}}+T_{\mathrm{b}}}{\sqrt{N_{b} B \tau}}
$$

where $\tau$ is the integration interval, $B$ is the radiometer effective bandwidth, $T_{\mathrm{rec}}$ is the receiver noise temperature, and $N_{\mathrm{b}}$ is the number of beams. Since $T_{\mathrm{h}} \ll T_{\mathrm{v}}$, it is more affected by the erroneous power signal from land.

The required $\Delta T_{\min }$ can be achieved by making a trade-off between $N_{\mathrm{b}}$ for a given reflector diameter, and complexity of the feed. For a conically scanning antenna, rotating at 11.5 RPM, $N_{\mathrm{b}}$ in the along-track direction is selected such to cover the same strip width on the Earth at each frequency band. To reach the required $\Delta T_{\min }$ we need:

- 2 beams along track at $6.9 \mathrm{GHz}$

- 3 beams along track and 7 beams across track at $10.65 \mathrm{GHz}$

- 5 beams along track and 6 beams across track at $18.7 \mathrm{GHz}$

For a push-broom case, the antenna is stationary, and its $\Delta T_{\min }$ is about one order of magnitude better than the one for the scanner. This is at the expense of a very large $N_{\mathrm{b}}$, and correspondingly large number of receivers. For a swath of $600 \mathrm{~km}$ we need:

- 58 beams across track at $6.9 \mathrm{GHz}$

- 89 beams across track at $10.65 \mathrm{GHz}$

- 156 beams across track at $18.7 \mathrm{GHz}$

For both cases listed above, we have considered a FP overlap of $\sim 30 \%$ both along track and across track to assure accurate sampling of the temperature scene on-ground, and the values of $B$ and $T_{\text {rec }}$ as shown in the Table I and Table II [7].
TABLE II

ASSUMED NOISE CHARACTERISTICS OF THE RECEIVER

\begin{tabular}{|l|c|c|c|c|}
\hline \multirow{2}{*}{} & \multicolumn{2}{|c|}{ Conical scanner } & \multicolumn{2}{c|}{ Push-broom } \\
\cline { 2 - 5 } & $\mathrm{NF}$ & $T_{\text {rec }}$ & $\mathrm{NF}$ & $T_{\text {rec }}$ \\
\hline $\mathrm{C}$ band & $2.5 \mathrm{~dB}$ & $226 \mathrm{~K}$ & $3.5 \mathrm{~dB}$ & $359 \mathrm{~K}$ \\
\hline $\mathrm{X}$ band & $2.5 \mathrm{~dB}$ & $226 \mathrm{~K}$ & $3.5 \mathrm{~dB}$ & $359 \mathrm{~K}$ \\
\hline Ku band & $3.0 \mathrm{~dB}$ & $290 \mathrm{~K}$ & $4.0 \mathrm{~dB}$ & $438 \mathrm{~K}$ \\
\hline
\end{tabular}

\section{REFLECTOR ANTENNA DESIGN}

To cover the required $600 \mathrm{~km}$ swath on the Earth surface, a beam scan about $\pm 20^{\circ}$ is needed. Due to high aberrations stationary single-parabolic-reflector configurations are not suitable for such tasks. To solve this issue, one option is to consider a rotating reflector assembly as done for the Soil Moisture Active Passive (SMAP) mission [8], [9], but that goes at the cost of low integration time spent over a footprint (thus low radiometric resolution $\Delta T_{\min }$ ) and increased complexity of the satellite platform which must support mechanically rotating reflector system. Another option is to use non-conventional toroidal reflector, which has already been investigated in late 80 's with a cluster feed of horns [11]. Such a radiometer configuration is stationary and provides high radiometric sensitivity thanks to many simultaneous beams, however a much more complex receiver must be implemented, comparing to the conical scan configuration.

We have investigated different reflector systems, including conventional off-set parabolic reflectors with circular and elliptical apertures as the conical scanner, and toroidal singleand dual-reflector antennas for the push-broom concept. The sections below describe the selected conical scanner and pushbroom antenna implementations.

The conical scan antenna is a conventional offset paraboloid with projected aperture $\mathrm{D}$ of $5 \mathrm{~m}$ and circular rim. The clearance is set to 1 meter in order to provide space for the feed cluster and the focal length $f$ is set to $3 \mathrm{~m}$ in order to make the design more compact.

The push-broom antenna is a torus reflector with projected aperture $D$ of $5 \mathrm{~m}$. The torus is obtained by rotating a section

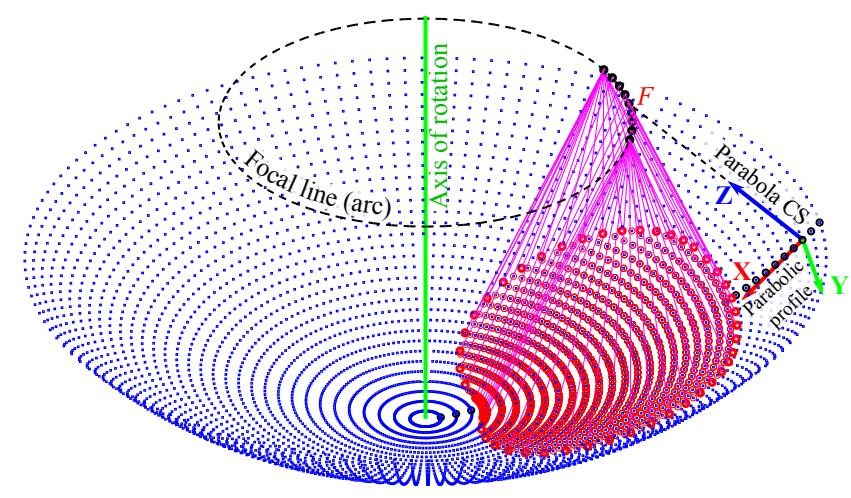

Fig. 3. Design procedure of a parabolic torus reflector (red surface): the parabolic profile (black circles at the bottom), defined in the coordinate system "Parabola CS" and with focal point $F$, is rotated around the green axis of rotation which itself is tilted with respect to the parabola axis. This transforms the profile focal point $F$ to the focal line (arc) along which a PAF will be positioned. The arc angle defines the maximum beam scan angle and, correspondingly, the swath width. 
of a parabolic arc around a rotation axis. The focal length of the parabolic generator is also $5 \mathrm{~m}$. A possible way of obtaining the torus is shown in Fig. 3: the feed axis is selected parallel to the rotation axis, implying that all feed element axes are parallel and orthogonal to the focal plane. The array feed becomes therefore planar, simplifying the mechanical and electrical design. The antenna shall be able to provide a scan of $\pm 20^{\circ}$ corresponding to a swath width of $600 \mathrm{~km}$. The reflector rim is found by intersecting the torus surface by the feed cone up to the out-most scan positions of $20^{\circ}$ and $-20^{\circ}$ (see Fig. 3 in [12]). The antenna projected aperture is $5 \times 7.5 \mathrm{~m}$.

\section{Conical scanner}

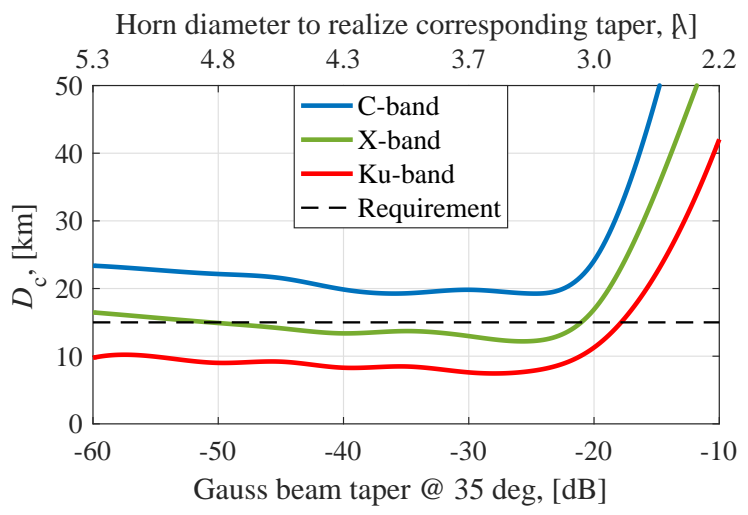

(a)

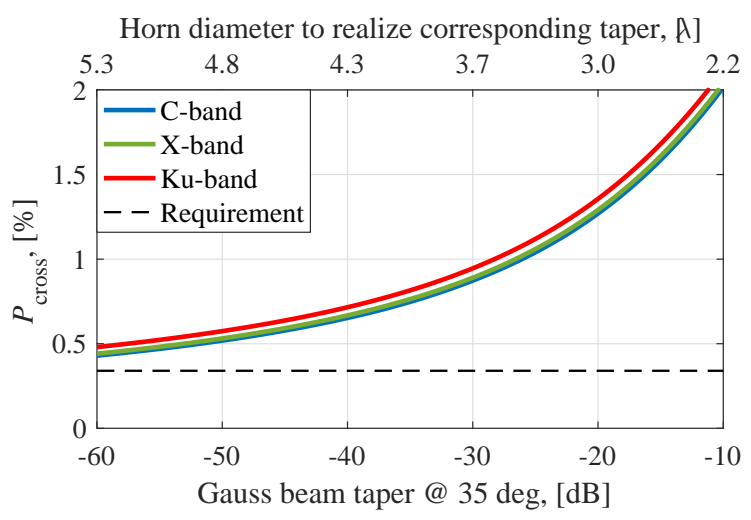

(b)

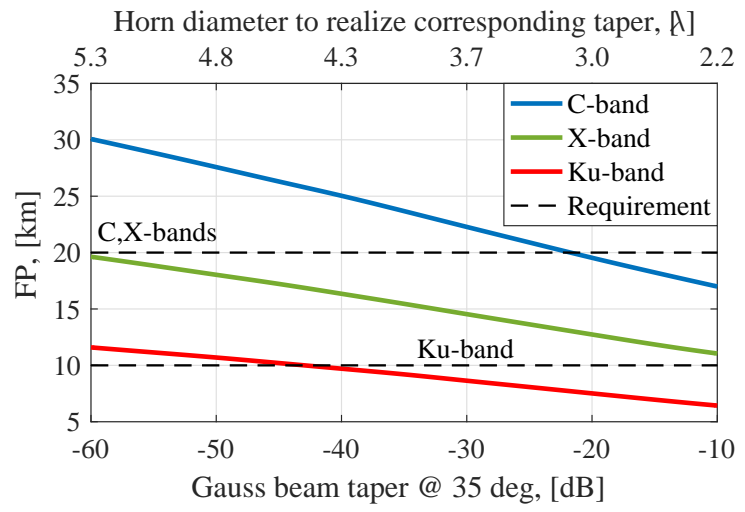

(c)
A more detailed explanation of the design procedure of the torus reflector can be found in [11].

\section{LIMITATIONS OF CLUSTER FEEDS OF HORNS}

Cluster feeds for space-borne multi-frequency radiometers are typically designed to provide a Gaussian type beam with strong illumination taper toward the edge of the reflector (when seen in transmit situation) in order to maximize the antenna beam efficiency and minimize the side-lobe and crosspolarization power [30]. A typical example of such feeds is a conical horn antenna. This approach, however, leads to (i) the

\section{Push-broom}

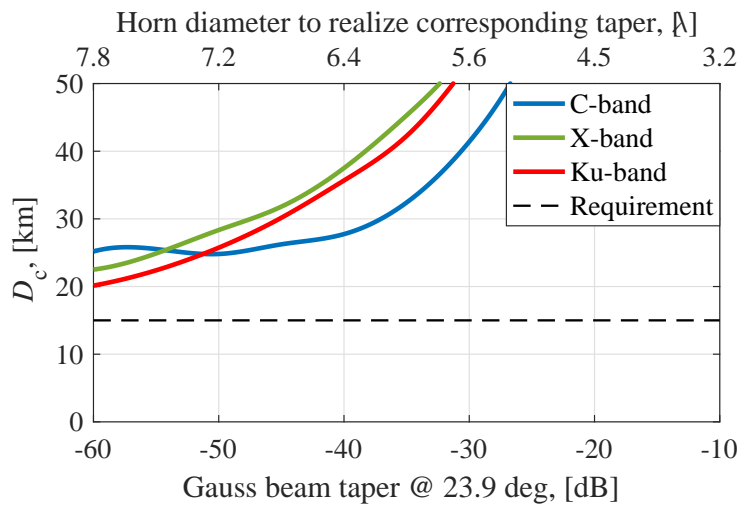

(d)

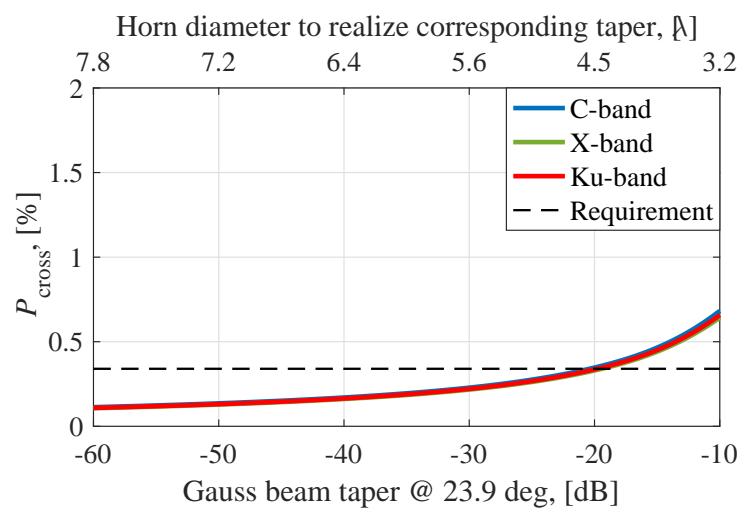

(e)

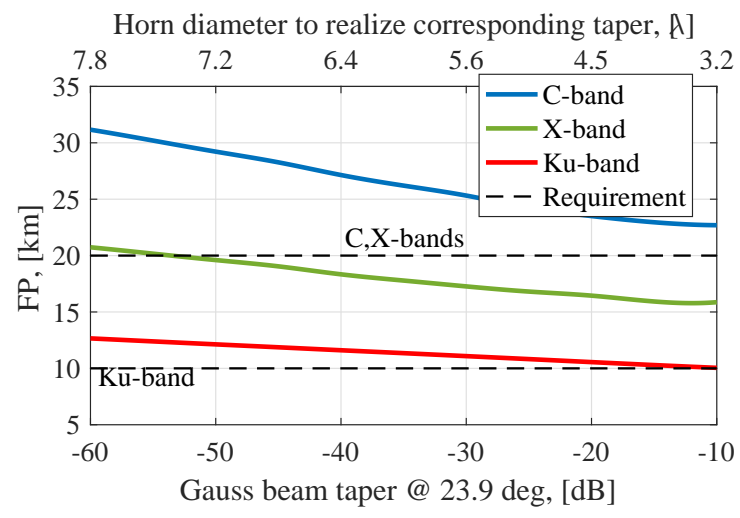

(f)

Fig. 4. Radiometer characteristics, i.e. the distance-to-land, relative cross-polarization power and footprint size, as function of the illumination taper of the Gaussian feed for (a-c) the conical scanner and (d-f) push-broom antenna configuration. The corresponding aperture diameter of the optimal circular horn [28], [29] is shown on the top axis. 
lower spatial resolution due to the widening of the footprint; and (ii) the difficulty to accommodate several feeds due to their large apertures, and hence several bands. Figs 4(a-c) and 4(d-f) illustrate these limitations for the considered scanner and pushbroom systems, respectively. As seen, $P_{\text {cross }}$ of the scanner can only be minimized by employing a feed with the aperture diameter larger than $5 \lambda$ and illumination taper that is $<60 \mathrm{~dB}$ at $35^{\circ}$. This gives FP $>30 \mathrm{~km}$ and $D_{\mathrm{c}}>23 \mathrm{~km}$ at C-band, while FP $=20 \mathrm{~km}$ and $D_{\mathrm{c}}=5-15 \mathrm{~km}$ are desired. The shortest $D_{\mathrm{c}}$ that can be achieved is $\sim 20 \mathrm{~km}$, for which the realized $P_{\text {cross }}$ is at least 3 times higher than the desired $0.34 \%$. At higher frequency bands, realizing the required $D_{\mathrm{c}}$ is not a problem, as the side-lobe levels can be significantly reduced (see Fig. 6(c)) by under-illuminating the reflector aperture, while providing $\mathrm{FP}=10 \mathrm{~km}$. However, the cross-polarization power is not acceptable.

For the push-broom system, the dependence of the radiometer characteristics from the illumination taper is similar to that of the scanner, and even larger feed apertures are needed due to the more shallow surface of the reflector. The main challenges for this system are attributed to the complex shape of the torus reflector, and, as the result, more complex focal field (compare Figs 5(a) and 5(b)). The high coma-side lobes and non-circular main lobe of the focal field distribution of the torus reflector (see Fig. 5(b)) cannot be accurately sampled by a single (horn) antenna feed; and this is the reason of the high side-lobe of the antenna far-field pattern (see Figs. 7(ac)), and hence too large distance-to-coast. In contrast, dense FPAs are capable of handling these complexities, as will be demonstrated in the following section.

\section{Dense Focal Plane Arrays}

\section{A. Array models and configurations}

Based on the requirements derived in Sec. II, three FPAs of half-wavelength dipole antenna elements covering C-, X- and Ku-bands have been designed for each radiometer. First, we computed the focal fields of several plane waves corresponding to the desired beam directions, and then used these to derive the minimum aperture sizes of FPAs and their positions in

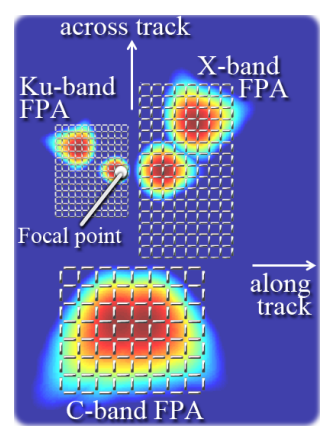

(a)

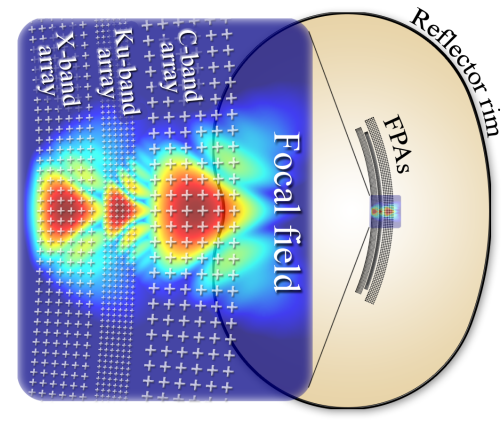

(b)
Fig. 5. Example of focal field distributions due to multiple plane waves incident on (a) the conical scan reflector antenna and (b) torus reflector antenna at $\mathrm{C}$-, $\mathrm{X}$ - and $\mathrm{Ku}$-bands, as calculated using the Physical Optics software GRASP10. For each frequency band the array layout is overlaid above one (for push-broom) or two (for conical scanner) focal field distributions.
TABLE III

NUMBER OF ELEMENTS

\begin{tabular}{|l|c|c|}
\hline & Conical scanner & Push-broom \\
\hline Array grid & rectangular & polar \\
\hline $\mathrm{C}$ band & $64+63=127$ & $6 \times 111 \times 2=1332$ \\
\hline $\mathrm{X}$ band & $128+135=263$ & $6 \times 153 \times 2=1836$ \\
\hline Ku band & $165+168=333$ & $6 \times 255 \times 2=3060$ \\
\hline
\end{tabular}

the focal regions, as shown in Fig. 5. After that, a parametric study was carried out to determine the minimum needed $N_{\mathrm{el}}$ and the corresponding inter-element separation distance $d_{\mathrm{el}}$. Note that to reduce the computational time, we have simplified the original MoM array model by assuming that all embedded element patterns (EEPs) are identical to that of the central element (the validity of this assumption will be confirmed in Sec. V-D). The EEPs for each unique set of $N_{\mathrm{el}}$ and element positions were imported into the reflector antenna software GRASP10 to compute the secondary EEPs, which, in turn, were used to determine the optimum element excitation coefficients that will be discussed further. Table III summarizes the results of this parametric study. As one can see, for the conical scanner we need 127, 263 and 333 antenna elements for the C- X- and Ku-band, respectively, to provide 2, 21 and 30 beams. Since the radiometric resolution of the push-broom system is much higher (due to many more beams), as one can expect, this comes at the expenses of more elements. It is important to note that the required numbers of elements, determined through this optimization procedure, are almost twice smaller than when applying a conventional conjugatefield-matching optimization approach (see Table 3 in [12]).

For both systems, the optimal $d_{\mathrm{el}}$ is near $0.75 \lambda$; this value satisfies the grating-lobe free condition [13] and also minimizes the active impedance variation of antenna elements due to their non-identical excitation [31], [32].

\section{B. Choice of the array radiating element}

The main requirements for the array radiating element are that (i) it should be small enough to design the array with interelement spacing less than $0.75 \lambda$ in order to avoid the grating lobes [13]; and (ii) it should be possible to use in a dualpolarization configuration. Since the relative bandwidth required for the ocean remote sensing do not exceed $5 \ldots 10 \%$, it is not critical for element selection.

For arrays with the inter-element spacing in the order of half wavelength, the optimal number of elements has been found weakly dependent from the element type, but primarily set by:

- element excitation coefficients [33];

- area of the array aperture, which depends the focal field power region to be intercepted by the array feed for meeting the beam requirements [13];

- inter-element spacing in the array, which should be small enough for the accurate focal field sampling [13].

Other practical implementation requirements include a good impedance match between the antenna elements and amplifiers to minimize the receiver noise, robust and low weight spacequalified design. 
TABLE IV

COMPARISON OF THREE RADIATING ELEMENTS: CUTS OF THE EMBEDDED ELEMENT PATTERN OF THE PAF CENTRAL ELEMENT, OPTIMAL EXCITATION COEFFICIENTS OF THE ARRAY ELEMENTS, AND CORRESPONDING RADIOMETER CHARACTERISTICS. THE RESULTS ARE FOR THE PUSH-BROOM SYSTEM AT C-BAND ${ }^{1}$.

\begin{tabular}{|l|l|l|l|l|l|l|l|}
\hline Characteristic & $\begin{array}{l}\text { Require- } \\
\text { ment }\end{array}$
\end{tabular}

${ }^{1}$ The radiometer characteristics for the PAF of dipole elements are slightly different from the ones in Table V due to different selected parameters of the beamformer.

For the purpose of this study, i.e. to investigate different reflector systems at several frequency bands, it is sufficient to consider a simple half-wavelength dipole element when evaluating a complete set of radiation patterns and radiometer characteristics. For cross-comparison, we will show some selected results for the push-broom antenna at X-band for three different element types, which are (i) a half-wavelength dipole antenna; (ii) RUAG's patch-excited cup [34], and; (iii) a Vivaldi antenna [35]. These results are summarized in Table IV, which include (i) embedded element pattern cuts of the FPA central element; (ii) the optimal excitation coefficients of co- and cross-polarized array elements, and; (iii) corresponding radiometer characteristics.

It is interesting to observe that despite the fact that all the element types have different embedded element patterns (especially for the cross-polarization field component), the values of predicted radiometer characteristics differ insignificantly. The reason for that is the capability of the beamformer to compensate for these differences in the patterns.

Another interesting observation can be made about the cross-polarization power for each radiating element. Despite the cross-polarization level within the reflector subtended angle is the lowest for the PAF of dipole elements and the largest for the Vivaldi PAF (see the embedded element patterns in Table IV), the power contained in the cross-polarized field component after beamforming behaves in opposite way, i.e., it is the smallest for the Vivaldi PAF (see "Rel. cross-pol. power" row in Table IV). This can be explained by the capability of the beamformer to use orthogonal array elements to compensate for the cross-polarized component of the secondary field, which is generated by the array elements and reflector itself. This can be seen from the excitation coefficients, where the cross-polarized elements are most strongly excited for the Vivaldi array.

\section{Optimization procedure for element excitation}

In Sec. II, it has been shown that the antenna far-field beam should contains $99.72 \%$ of the total power within a circular cone with half angle $\theta_{\mathrm{c}}$ to realize the desired $D_{\mathrm{c}}$. The goal is, therefore, to determine the excitation coefficients such that the angle $\theta_{\mathrm{c}}$ becomes as small as possible, i.e. $D_{\mathrm{c}}$ is minimized.

The far field from the reflector antenna can be written as

$$
\boldsymbol{E}_{\mathrm{far}}(\theta, \phi)=\sum_{i=1}^{N_{\mathrm{el}}} \alpha_{i} \boldsymbol{E}_{\mathrm{far}, i}(\theta, \phi),
$$

where $\boldsymbol{E}_{\mathrm{far}, i}$ is the field due to element $i, N_{\mathrm{el}}$ is the total number of elements; and $\alpha_{i}$ is the corresponding complex 
excitation coefficient. The radiated power within the cone of half-angle $\theta_{\mathrm{c}}$ can be written as

$$
P_{\mathrm{c}}\left(\theta_{\mathrm{c}}\right)=\int_{0}^{2 \pi} \int_{0}^{\theta_{\mathrm{c}}}\left|\boldsymbol{E}_{\mathrm{far}}(\theta, \phi)\right|^{2} \sin \theta \mathrm{d} \theta \mathrm{d} \phi,
$$

If the expression (9) is inserted in (10) it is seen that it becomes a quadratic polynomial in the $\alpha_{i}$ variables and can be written in the form

$$
P_{\mathrm{c}}\left(\theta_{\mathrm{c}}\right)=\boldsymbol{\alpha}^{H} \mathbf{A} \boldsymbol{\alpha},
$$

where $\boldsymbol{\alpha}=\left[\alpha_{1}, \alpha_{2}, \ldots, \alpha_{N}\right]^{T}$ and $H$ is Hermitian operator. The matrix $\mathbf{A}$ is Hermitian of size $N_{\mathrm{el}} \times N_{\mathrm{el}}$ such that the expression in (11) becomes a real number. Note that the matrix A is a function of $\theta_{\mathrm{c}}$.

The power $P_{\mathrm{c}}\left(\theta_{\mathrm{c}}\right)$ in (10) must be related to the total radiated power from the feed array. This power, $P_{\text {tot }}$, can be computed from the expression (10) if $\theta_{\mathrm{c}}$ is replaced by $\pi / 2$ and the reflector patterns $\boldsymbol{E}_{\mathrm{far}, i}$ are replaced by the array element patterns $\boldsymbol{E}_{\text {far,array }, i}$. Again the power $P_{\text {tot }}$ becomes a quadratic polynomial in the variables $\boldsymbol{\alpha}$ such that

$$
P_{\text {tot }}=\boldsymbol{\alpha}^{H} \mathbf{C} \boldsymbol{\alpha},
$$

For a given value of $\theta_{\mathrm{c}}$ it is thus desired to find the excitations $\boldsymbol{\alpha}$ that maximize the ratio

$$
\frac{P_{\mathrm{c}}\left(\theta_{\mathrm{c}}\right)}{P_{\mathrm{tot}}}=\frac{\boldsymbol{\alpha}^{H} \mathbf{A} \boldsymbol{\alpha}}{\boldsymbol{\alpha}^{H} \mathbf{C} \boldsymbol{\alpha}},
$$

It can be shown that the maximum value of this ratio is the maximum eigenvalue $\lambda$ of the expression

$$
\mathbf{A} \boldsymbol{\alpha}=\lambda \mathbf{C} \boldsymbol{\alpha},
$$

and that the vector holding the complex excitation coefficients are given by the corresponding eigenvector.

The present optimisation method is similar to the one reported in [14] - which is based on a more general SignalTo-Noise-Ratio algorithm - but simpler to implement. Since for the considered application scenario, the optimization is strongly driven by the acceptable side-lobe and crosspolarization power of the antenna, the radiometric performances obtained by the two algorithms are very similar.

\section{Antenna patterns and radiometric characteristics}

Dense FPAs offer more degrees of freedom in beamforming, as compared to conventional feeds, and thereby can provide highly optimized beams with more circular-symmetric main lobes and much lower cross polarization and sidelobe levels, as demonstrated in Figs 6(d-f) and 7(d-f). This results in significantly better radiometric characteristics for both systems. As one can see in Table V, the realized $D_{\mathrm{c}}$ of the conical scanner is $6.6-14 \mathrm{~km}$ and $P_{\text {cross }}$ is only $0.10-0.15 \%$ (i.e. about one order of magnitude better than for the horn feed); for the push-broom radiometer, the respective quantities are less than $16 \mathrm{~km}$ (while the horn feed cannot fulfill this requirement) and $0.08-0.12 \%$ (i.e. 3 times better than the horn feed). Furthermore, the latter system has wide scan-range performance, where the characteristics of all multiple beams within the angular range of \pm 20 deg are virtually identical, thanks to the symmetry of the torus reflector in the azimuthal plane and the moon-like shape of the FPA that matches the focal line of the reflector (see Fig. 5(b)).

The accuracy of the above analysis (that is based on the assumption of identical array element patterns) has been evaluated by cross-comparing the antenna patterns and corresponding radiometric characteristics with those obtained through the full MoM model. Fig. 8 shows the results for C-band, as the worse case scenario among the considered ones. As seen, the relative difference between the far-field patterns obtained with the simplified and more rigorous FPA models is negligible, so as the difference between the corresponding sets of radiometric characteristics (see Table V). This observation might appear counter-intuitive, given a significant variation between the embedded element patterns (EEPs) of the array, as shown in Fig. 8(a). However, one should realize that the optimal pattern of the feed leading to the minimum distance to land represents a combined effect of the EEPs and element excitation coefficients. Hence, when the optimization algorithm is applied to the set of non-identical EEPs, the excitation coefficients are modified with respect to that determined for the identical EEP case. For the considered arrays with more than 100 dipole antenna elements, the resultant optimal feed patterns have been found very similar for both array models (see the example for C-band in Fig. 8(b,c)). This observation, however, may not be valid for arrays with fewer and denser-spaced elements.

\section{RECEIVER CONSIDERATIONS}

In this section, we briefly consider receiver resource requirements in order to see if implementation of the present antenna concept is feasible and realistic. We consider the receiver where the signals from different antenna elements contribute to more than one beam, and each antenna element is connected to its own receiver, followed by an A/D converter. The beamforming process takes place in an Field Programmable Gate Array (FPGA), using complex digital multipliers and adders. Both the scanner and the push-broom system require a large number of elements to fulfill the radiometric requirements. Hence resource requirements concerning the size, mass and especially power consumption, is an important issue.

A study of state-of-the-art microwave components, assuming a super-heterodyne receiver (see Fig.7 in [37]), has been carried out. It has been found that at the considered frequency bands, most components are small and light weight, and thus volume and mass are not deemed to be a problematic issue. Power consumption has dropped dramatically over the past decade, and $1 \mathrm{~W}$ per receiver is now a realistic estimate. Furthermore, the output signals from FPA elements have to be optimally combined in a dedicated beamforming network to form the desired antenna beams. This involves a number of FPGAs and the average power consumption is estimated to be $0.24 \mathrm{~W}$ per receiver. Future radiometers must include intelligent RFI detection and mitigation processors. Based on a representative case study of such a processor [38], the power consumption can be estimated to be $0.14 \mathrm{~W}$ per receiver.

In summary, the power estimate is: $1+0.24+0.14=1.38 \mathrm{~W}$ per receiver, using present state-of-the-art components. The 


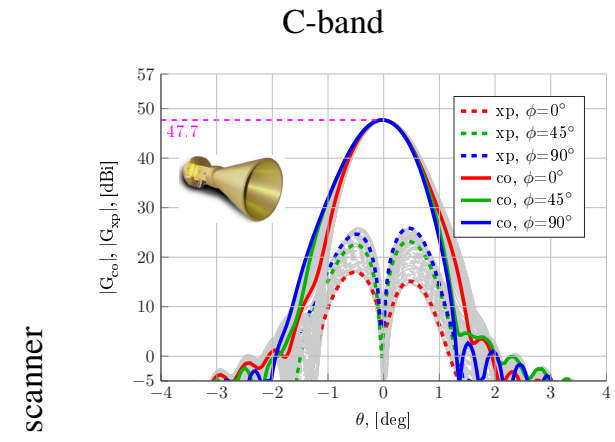

(a)

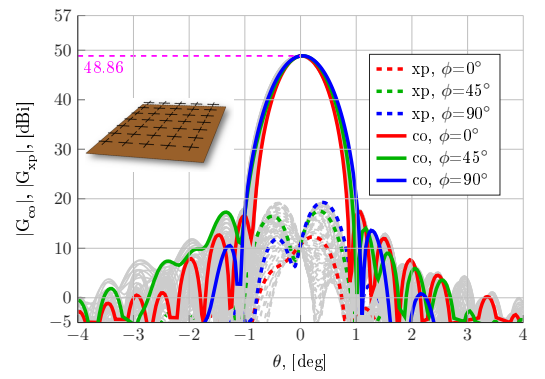

(d)
X-band

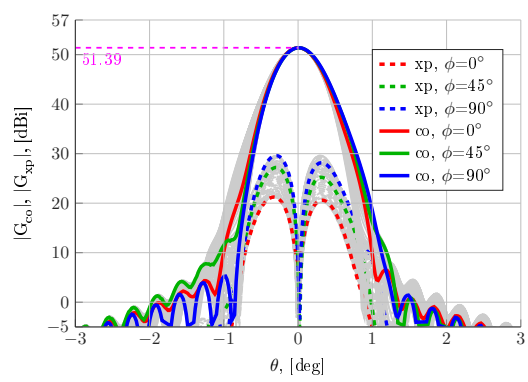

(b)

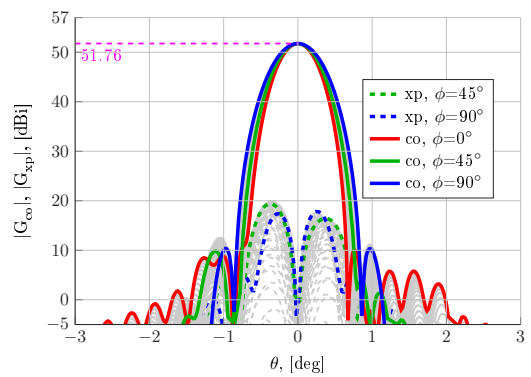

(e)
Ku-band

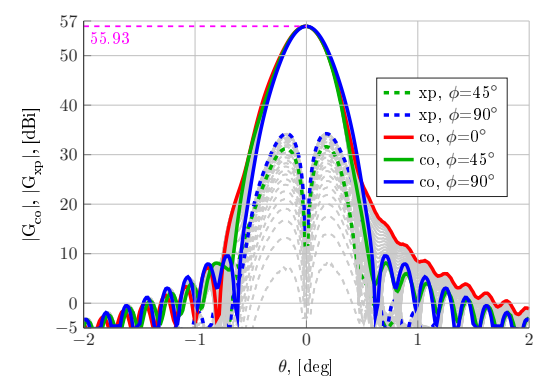

(c)

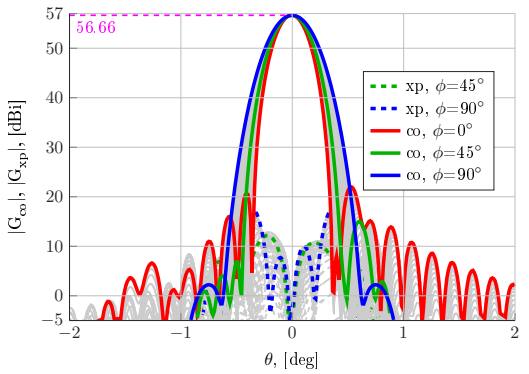

(f)

Fig. 6. Far-field pattern cuts for the conical scanner antenna at (a,d) C-band, (b,e) X-band, and (c,f) Ku-band, when the feed is (a-c) the Gaussian horn feed illuminating the reflector edge with the taper $-30 \mathrm{~dB}$, and (d-f) FPA with the optimum beamforming. The grey lines denote $\theta$-cuts for $\phi$ varying from $0^{\circ}$ to $180^{\circ}$ with step $2.5^{\circ}$.

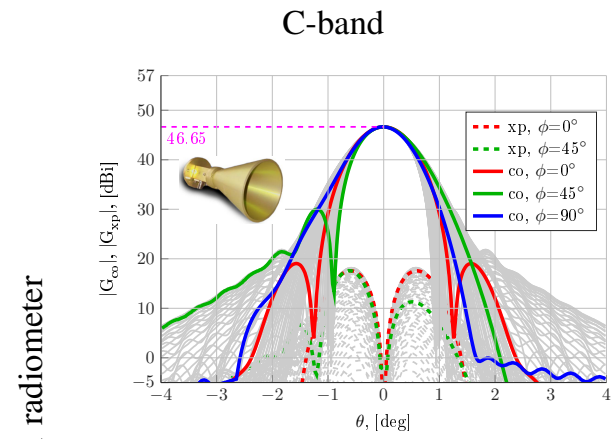

(a)

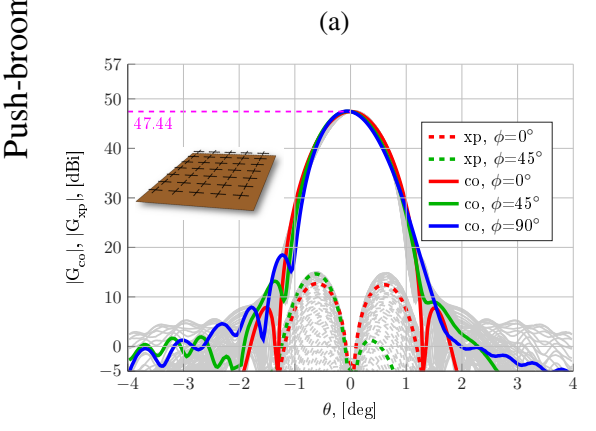

(d)

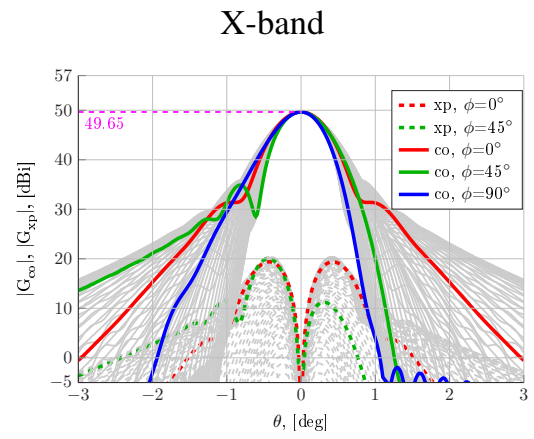

(b)

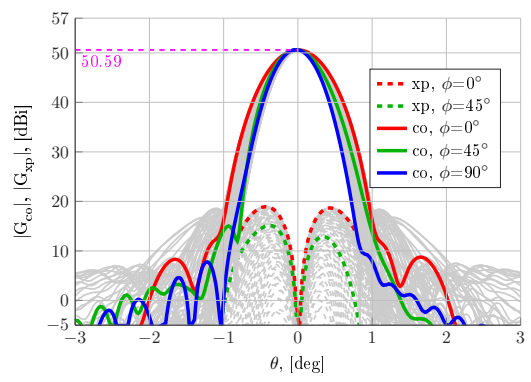

(e)

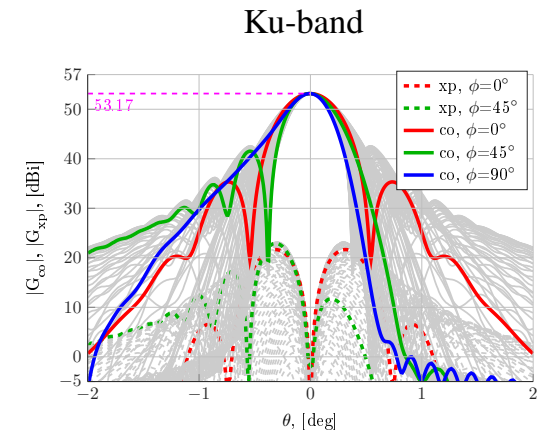

(c)

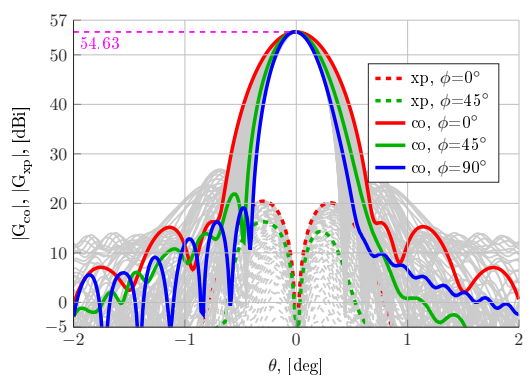

(f)

Fig. 7. Far-field pattern cuts for the push-broom radiometer antenna at (a,d) C-band, (b,e) X-band, and (c,f) Ku-band, when the feed is (a-c) the Gaussian horn feed illuminating the reflector edge with the taper $-30 \mathrm{~dB}$, and (d-f) FPA with the optimum beamforming. The grey lines denote $\theta$-cuts for $\phi$ varying from $0^{\circ}$ to $180^{\circ}$ with step $2.5^{\circ}$.

total number of receivers is 6228 in the push-broom case. This results in a total power consumption of $8.6 \mathrm{~kW}$, which is not realistic today. For the scanner with 723 receivers, the estimate is $1000 \mathrm{~W}$ - a large number, but feasible.
The present study is a preparation for the future, and it is of interest to base a power budget on realistic developments over a 5 years time frame. Already now, A/D converters able to sub-sample signals up to X-band are available in research 
TABLE V

RADIOMETRIC CHARACTERISTICS OF THE CONICAL SCANNER AND PUSH-BROOM SYSTEMS FOR THE GAUSSIAN HORN AND FPA. THE VALUES IN BRACKETS ARE FOR THE FULL MOM ARRAY MODEL, AND THE OTHER VALUES ARE WHEN ASSUMING IDENTICAL EMBEDDED ELEMENT PATTERNS

\begin{tabular}{|c|c|c|c|c|c|c|}
\hline \multirow{3}{*}{ Radiometer characteristic } & \multirow{3}{*}{$\begin{array}{c}\text { Require- } \\
\text { ment }\end{array}$} & \multicolumn{3}{|c|}{ Conical scanner } & \multicolumn{2}{|c|}{ Push-broom } \\
\hline & & \multirow{2}{*}{ Horn feed } & \multicolumn{2}{|c|}{ FPA } & \multirow{2}{*}{ Horn feed } & \multirow{2}{*}{ FPA } \\
\hline & & & Beam 1 & Beam 2 & & \\
\hline \multicolumn{7}{|c|}{ C-band } \\
\hline Distance to land, $[\mathrm{km}]$ & $<15$ & 19.2 & $14.2(14.2)$ & $14.2 \quad(14.2)$ & 41.4 & 16.1 \\
\hline Rel. cross-pol. power, $[\%]$ & $<0.34$ & 1.04 & $\begin{array}{ll}0.15 & (0.06)\end{array}$ & $0.10 \quad(0.07)$ & 0.23 & 0.08 \\
\hline Beam efficiency, [\%] & & 97.2 & $95.6 \quad(96.0)$ & $95.6 \quad(96.0)$ & 96.1 & 97.8 \\
\hline Footprint, $[\mathrm{km}]$ & $<20$ & 21 & $\begin{array}{ll}19.6 & (19.6)\end{array}$ & $\begin{array}{ll}19.6 & (19.6) \\
\end{array}$ & 25.3 & 23.1 \\
\hline Footprint ellipticity & & 1.64 & $1.43 \quad(1.44)$ & $1.44 \quad(1.44)$ & 1.57 & 1.48 \\
\hline \multicolumn{7}{|c|}{ X-band } \\
\hline Distance to land, $[\mathrm{km}]$ & $<15$ & 13.0 & 9.7 & 9.8 & 55.3 & 13.4 \\
\hline Rel. cross-pol. power, [\%] & $<0.34$ & 0.89 & 0.10 & 0.10 & 0.22 & 0.12 \\
\hline Beam efficiency, [\%] & & 97.7 & 98.2 & 97.4 & 95.0 & 98.4 \\
\hline Footprint, $[\mathrm{km}]$ & $<20$ & 14.5 & 14.2 & 14.2 & 17.3 & 15.9 \\
\hline Footprint ellipticity & & 1.64 & 1.32 & 1.38 & 1.48 & 1.21 \\
\hline \multicolumn{7}{|c|}{ Ku-band } \\
\hline Distance to land, $[\mathrm{km}]$ & $<15$ & 7.6 & 6.6 & 6.6 & 53.2 & 13.4 \\
\hline Rel. cross-pol. power, [\%] & $<0.34$ & 0.95 & 0.03 & 0.07 & 0.22 & 0.08 \\
\hline Beam efficiency, [\%] & & 97.7 & 97.4 & 97.2 & 84.5 & 98.0 \\
\hline Footprint, $[\mathrm{km}]$ & $<10$ & 8.6 & 8.0 & 8.2 & 11.1 & 10.0 \\
\hline Footprint ellipticity & & 1.67 & 1.24 & 1.35 & 1.27 & 1.05 \\
\hline
\end{tabular}

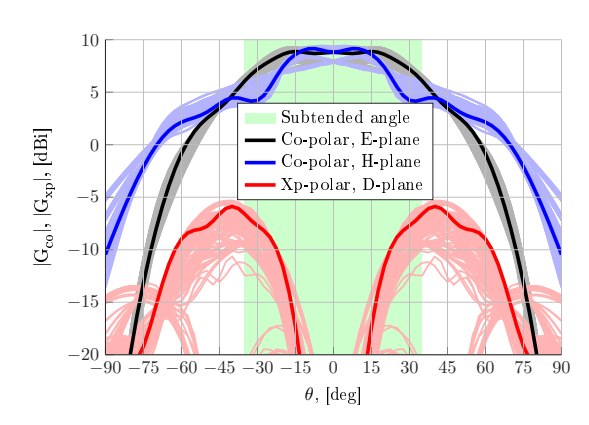

(a)

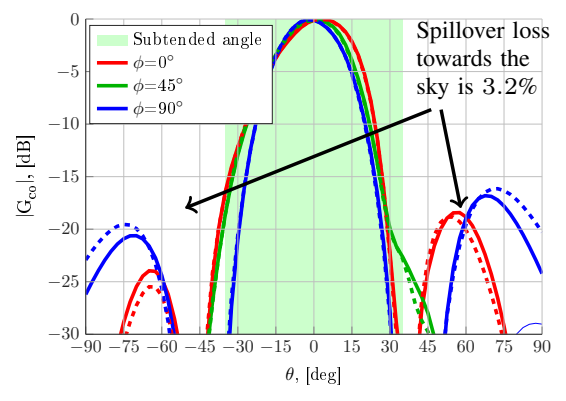

(b)

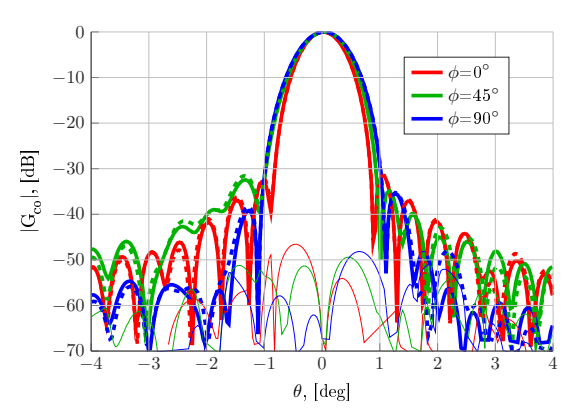

(c)

Fig. 8. (a) All embedded element patterns of the C-band FPA for the conical scanner at E-, H- and D-planes, as obtained through the Method of Moments in CAESAR software [36], where the bold lines correspond to the central antenna element of the array; (b) beamformed far-field pattern cuts of the FPA within the reflector subtended angle region for the conical scan antenna, and (c) far-field pattern cuts of the reflector antenna for beam 1 . The solid lines correspond to the MoM array model, dashed lines represent the model with the assumed identical embedded element patters of the array, and the thin solid lines show the relative normalized difference between the antenna patterns obtained with the above models.

labs, and within very few years Ku band is also possible. Thus we do not need the super-heterodyne layout, and the local oscillator and its power consumption, can be avoided. The new, fast $\mathrm{A} / \mathrm{D}$ converters use very small signal levels typically around $-35 \mathrm{dBm}$, and hence not much gain is needed in the receiver (also saving on power). The development concerning amplifier power consumption is also impressive. For global power budget estimates we can within a few years assume $\sim 35 \mathrm{~mW}$ per receiver. If we assume a similar reduction for processing circuitry, the result is $9 \mathrm{~mW}$ for the beam forming network, and $5 \mathrm{~mW}$ for the RFI processor, i.e. $49 \mathrm{~mW}$ per receiver. For the push-broom system this amounts to a total power consumption of $305 \mathrm{~W}$, which is certainly realistic. For the scanner the estimate is about $35 \mathrm{~W}$.

\section{CONCLUSIONS}

Existing space-borne microwave radiometers that are used for the assessment of ocean parameters like salinity, temperature, and wind can provide valid observations only up to $\sim 100 \mathrm{~km}$ from the coastline, and hence do not allow for monitoring of the coastal areas and ice-edge polar seas, and measuring under extreme wind and weather conditions. To achieve the desired precision, as required for future missions, we propose digitally-beamforming dense focal plane arrays (FPAs) - previously not used in space-borne applications, employed either in a traditional conical-scan off-set parabolic reflector antenna or in a wide-scan torus reflector system.

When synthesized and excited according to the proposed optimum beamforming procedure - aiming to minimize the signal contamination given by the side-lobes and crosspolarization of antenna beams covering the land, - the number of the FPA antenna elements and associated receivers can be kept to minimum. In this procedure, the input parameters include the number of array elements, their positions and the secondary embedded element patterns (EEPs), which are computed after the illumination of the reflector antenna, and the output parameters are the optimal complex-valued element excitations. Although, the primary EEPs are generally not identical, due to the array antenna mutual coupling and edge truncation effects, for the considered FPAs with more than 100 
dipole antenna elements and inter-element spacing of $0.75 \lambda$, it has been found sufficient to use a single primary EEP, i.e. the one for a central element of the array, as the source of the secondary EEPs for all elements in order to accurately predict the achievable radiometric characteristics.

For both types of radiometers, the realized resolutions are at least twice higher than the values provided by the current systems, and the distance to coastline is as short as $6-15 \mathrm{~km}$. This excellent performance was shown to be impossible with traditional multi-frequency FPAs of horns in one-horn-perbeam configuration, as these cannot compensate for the high cross-polarization of off-axis beams in conical-scanners, and produce unacceptably high side-lobes due to severe focal-field under-sampling effects in torus reflector systems.

Our analysis of realistic developments of digital processors predicts acceptable receiver resources budget for such multibeam radiometers within a 5 years time frame.

Future work will address space-qualified array design, and possible reduction of the array elements to minimize power consumption.

\section{ACKNOWLEDGMENT}

We would like to acknowledge RUAG Space (Johan Wettergren and Susanne Schilliger Kildal), Sweden, for providing us with the data for the patch-excited cup antenna.

\section{REFERENCES}

[1] C. Prigent, F. Aires, F. Bernardo, J.-C. Orlhac, J.-M. Goutoule, H. Roquet, and C. Donlon, "Analysis of the potential and limitations of microwave radiometry for the retrieval of sea surface temperature: Definition of MICROWAT, a new mission concept," Geophys. Res. Oceans, vol. 118, pp. 3074-3086, Jun. 2013.

[2] E. V. Zabolotskikh, L. M. Mitnik, and B. Chapron, "New approach for severe marine weather study using satellite passive microwave sensing," Geophys. Res. Lett., vol. 40, pp. 3347-3350, Jul. 2013.

[3] N. Reul, B. Chapron, T. Lee, C. Donlon, J. Boutin, and G. Alory, "Sea surface salinity structure of the meandering Gulf stream revealed by SMOS sensor," Geophys. Res. Lett., vol. 41, pp. 3141-3148, May 2014.

[4] STSE - High Resolution Microwave Wind and Temperature (MICROWAT). [Online]. Available: https://www.yumpu.com/en/document/view/10779401/downloaddocument-microwat

[5] P. W. Gaiser, "The WindSat spaceborne polarimetric microwave radiometer: Sensor description and early orbit performance," IEEE Trans. Geo. Rem. Sensing, vol. 42, no. 11, pp. 591-603, Nov. 2004.

[6] Amsr-e instrument description. [Online]. Available: http://nsidc.org/data/docs/daac/amsre_instrument.gd.html

[7] N. Skou and D. L. Vine, Microwave Radiometer Systems: Design \& Analysis. Artech House, 2006.

[8] M. Mobrem, E. Keay, G. Marks, and E. Slimko, "Development of the large aperture reflector/boom assembly for the SMAP spacecraft," in ESA/ESTEC Workshop on Large Deployable Antennas, Noordwijk, The Netherlands, Oct. 2012.

[9] SMAP handbook - Soil Moisture Active Passive. [Online]. Available: https://smap.jpl.nasa.gov/system/internal_resources/details/original/ 178_SMAP_Handbook_FINAL_1_JULY_2014_Web.pdf

[10] R. Hoferer and Y. Rahmat-Samii, "RF characterization of an inflatable parabolic torus reflector antenna for space-borne applications," IEEE Trans. Antennas Propag., vol. 46, no. 10, pp. 1449-1457, Oct. 1998.

[11] P. Nielsen, K. Pontoppidan, J. Heeboell, and B. L. Stradic, "Design, manufacture and test of a pushbroom radiometer," in Antennas and Propagation, 1989. ICAP 89., Sixth International Conference on (Conf. Publ. No.301), Coventry, United Kingdom, Apr. 1989, pp. 126-130.

[12] C. Cappellin, K. Pontoppidan, P. Nielsen, N. Skou, S. S. Søbjærg, A. Ihle, D. Hartmann, M. Ivashina, O.Iupikov, and K. v. t Klooster, "Novel multi-beam radiometers for accurate ocean surveillance," in Proc. European Conference on Antennas and Propag. (EuCAP), The Hague, The Netherlands, Apr. 2014, pp. 1-4.
[13] O. A. Iupikov, M. V. Ivashina, K. Pontoppidan, P. H. Nielsen, C. Cappellin, N. Skou, S. S. Søbjærg, A. Ihle, D. Hartmann, and K. v. t Klooster, "Dense focal plane arrays for pushbroom satellite radiometers," in Proc. European Conference on Antennas and Propag. (EuCAP), Hague, The Netherlands, Apr. 2014, pp. 1-5.

[14] _ "An optimal beamforming algorithm for phased-array antennas used in multi-beam spaceborne radiometers," in Proc. European Conference on Antennas and Propag. (EuCAP), Lisbon, Portugal, Apr. 2015 , pp. 1-5.

[15] C. Cappellin, K. Pontoppidan, P. H. Nielsen, N. Skou, S. S. Søbjærg, A. Ihle, M. V. Ivashina, O. A. Iupikov, and K. v. 't Klooster, "Design of a push-broom multi-beam radiometer for future ocean observations," in Proc. European Conference on Antennas and Propag. (EuCAP), Lisbon, Portugal, Apr. 2015, pp. 1-5.

[16] J. Fisher and R. Bradley, "Full-sampling array feeds for radio telescopes," in Proc. SPIE, Radio Telescopes, vol. 4015, Munich, Germany, Jul. 2000, pp. 308-318.

[17] K. F. Warnick, D. Carter, T. Webb, B. D. Jeffs, J. Landon, V. Asthana, M. Elmer, R. Norrod, D. A. Roshi, and J. R. Fisher, "Towards a high sensitivity cryogenic phased array feed antenna for the Green Bank Telescope," in XXXth URSI General Assembly and Scientific Symposium, Istanbul, Turkey, Aug. 2011, pp. 1-4.

[18] D. R. DeBoer, R. G. Gough, J. D. Bunton, T. J. Cornwell, R. J. Beresford, S. Johnston, I. J. Feain, A. E. Schinckel, C. A. Jackson, M. J. Kesteven, A. Chippendale, G. A. Hampson, J. D. O’Sullivan, S. G. Hay, C. E. Jacka, T. W. Sweetnam, M. C. Storey, L. Ball, and B. J. Boyle, "Australian SKA pathfinder: A high-dynamic range wide-field of view survey telescope," Proc. IEEE, vol. 97, no. 8, pp. 1507-1521, Aug. 2009.

[19] B. Veidt, T. Burgess, R. Messing, G. Hovey, and R. Smegal, "The DRAO phased array feed demonstrator: Recent results," in 13th Int. Symp. on Antenna Technology and Applied Electromagnetics and the Canadian Radio Science Meeting, ANTEM/URSI 2009, Banff, Canada, Feb. 2009, pp. $1-4$.

[20] M. V. Ivashina, O. Iupikov, R. Maaskant, W. A. van Cappellen, and T. Oosterloo, "An optimal beamforming strategy for wide-field surveys with phased-array-fed reflector antennas," IEEE Trans. Antennas Propag., vol. 59, no. 6, pp. 1864-1875, Jun. 2011.

[21] Y. Wu, X. Zhang, B. Du, C. Jin, L. Zhang, and K. Zhu, "Design of antenna array for the L-band phased array feed for FAST," in Antennas Propagation (ISAP), 2013 Proceedings of the International Symposium on, Nanjing, China, Oct. 2013, pp. 11-13.

[22] K. F. Warnick, R. Maaskant, M. V. Ivashina, D. B. Davidson, and B. D. Jeffs, "High-sensitivity phased array receivers for radio astronomy," Proceedings of the IEEE, vol. 104, no. 3, pp. 607-622, Mar. 2016.

[23] (2017) Boeing: Satellite Development Center Geo-Mobile - Thuraya-2,3. [Online]. Available: http://web.archive.org/web/20120509231723/http://www.boeing.com/defensespace/space/bss/factsheets/geomobile/thuraya2_3/thuraya2_3.html

[24] (2017) Inmarsat - Our satellites. [Online]. Available: https://www.inmarsat.com/about-us/our-satellites/

[25] M. Schneider, C. Hartwanger, E. Sommer, and H. Wolf, "The multiple spot beam antenna project "Medusa"," in Proc. European Conference on Antennas and Propag. (EuCAP), Berlin, Germany, Mar. 2009, pp. 726-729.

[26] M. Schneider, C. Hartwanger, and H. Wolf, "Antennas for multiple spot beam satellites," CEAS Space Journal, vol. 2, no. 1, pp. 1868-2510, Dec. 2011.

[27] P. Bosshard, J. Lafond, F. Dubos, P. Lepeltier, E. Vourch, F. Delepaux, C. Labourdette, L. Martin, G. Navarre, and C. Feat, "Thales Alenia Space HTS/V-HTS Multiple Beam Antennas sub-systems on the right track," in Proc. European Conference on Antennas and Propag. (EuCAP), Davos, Switzerland, Apr. 2016, pp. 1-5.

[28] T. Teshirogi and T. Yoneyama, Modern Millimeter-wave Technologies. IOS Press, 2001.

[29] P.-S. Kildal, Foundations of Antenna Engineering - A Unified Approach for Line-Of-Sight and Multipath. Kildal Antenn AB, 2015.

[30] S. Contu and F. M. Marinelli, "The antenna system for the multifrequency imaging microwave radiometer: M.I.M.R," in Antennas and Propagation Society International Symposium, 1994. AP-S. Digest, vol. 3, Seattle, WA, USA, Jun. 1994, pp. 2054-2057.

[31] M. Arts, M. Ivashina, O. Iupikov, L. Bakker, and R. van den Brink, "Design of a low-loss low-noise tapered slot phased array feed for reflector antennas," in Proc. European Conference on Antennas and Propag. (EuCAP), Barcelona, Spain, Apr. 2010, pp. 1-5.

[32] K. F. Warnick, D. Carter, T. Webb, J. Landon, M. Elmer, and B. D. Jeffs, "Design and characterization of an active impedance matched low-noise 
phased array feed," IEEE Trans. Antennas Propag., vol. 59, no. 6, pp. 1876-1885, Jun. 2011.

[33] M. V. Ivashina, M. Kehn, P.-S. Kildal, and R. Maaskant, "Decoupling efficiency of a wideband Vivaldi focal plane array feeding a reflector antenna," IEEE Trans. Antennas Propag., vol. 57, no. 2, pp. 373-382, Feb. 2009.

[34] J. Johansson and P. Ingvarson, "Array antenna activities at RUAG space: An overview," in Proc. European Conference on Antennas and Propag. (EuCAP), Gothenburg, Sweden, Apr. 2013, pp. 666-669.

[35] O. A. Iupikov, A. A. Roev, and M. V. Ivashina, "Prediction of farfield pattern characteristics of phased array fed reflector antennas by modeling only a small part of the array - Case study of spaceborne radiometer antennas," in Proc. European Conference on Antennas and Propag. (EuCAP), Paris, France, Mar. 2017, pp. 2636-2639.

[36] R. Maaskant, "Analysis of large antenna systems," Ph.D. dissertation, Electrical engineering, Eindhoven University of Technology, Eindhoven, 2010. [Online]. Available: http://alexandria.tue.nl/extra2/201010409.pdf

[37] N. Skou, S. S. Søbjærg, S. S. Kristensen, C. Cappellin, K. Pontoppidan, M. Ivashina, A. Ihle, and K. v.'t Klooster, "Future spaceborne ocean missions using high sensitivity multiple-beam radiometers," in IEEE International Geoscience and Remote Sensing Symposium (IGARSS), Québec City, Québec, Canada, Jul. 2014.

[38] N. Skou, S. Kristensen, A. Kovanen, and J. Lahtinen, "Processor breadboard for on-board RFI detection and mitigation in MetOp-SG radiometers," in Geoscience and Remote Sensing Symposium (IGARSS), 2015 IEEE International, Milan, Italy, Jul. 2015, pp. 1445-1448. 